Portland State University

PDXScholar

4-1-2019

\title{
Leveraging Variation of Historical Number Systems to Build Understanding of the Base-Ten Place-Value System
}

\author{
Eva Thanheiser \\ Portland State University, evat@pdx.edu \\ Kathleen Melhuish \\ Texas State University
}

Follow this and additional works at: https://pdxscholar.library.pdx.edu/mth_fac

Part of the Mathematics Commons

Let us know how access to this document benefits you.

\begin{abstract}
Citation Details
Thanheiser, E., \& Melhuish, K. (2019). Leveraging Variation of Historical Number Systems to Build Understanding of the Base-Ten Place-Value System. ZDM: The International Journal on Mathematics Education, 51(1), 39-55.
\end{abstract}

This Post-Print is brought to you for free and open access. It has been accepted for inclusion in Mathematics and Statistics Faculty Publications and Presentations by an authorized administrator of PDXScholar. Please contact us if we can make this document more accessible: pdxscholar@pdx.edu. 


\title{
Leveraging Variation of Historical Number Systems to Build Understanding of the Base-Ten Place-Value System
}

\author{
Eva Thanheiser \\ Portland State University \\ evat@pdx.edu \\ Kathleen Melhuish \\ Texas State University \\ melhuish@txstate.edu
}

\begin{abstract}
Prospective elementary school teachers (PTs) come to their mathematics courses fluent in using procedures for adding and subtracting multidigit whole numbers, but many are unaware of the essential features inherent in understanding the base-10 place-value system (i.e., grouping, place value, base). Understanding these features is crucial to understanding and teaching number and place value. The research aims of this paper are (1) to present a local instructional theory (LIT), designed to familiarize PTs with these features through comparison with historical number systems and (2) to present the effects of using the LIT in the PT classroom. A theory of learning (variation theory) is paired with a framework related to motivation (intellectual need) to illustrate the mutually supporting roles they may play in mathematical learning and task design. The LIT, a supporting task sequence, and the rationale for task design are shared. This theoretical contribution is then paired with evidence of PTs' changing grouth in their conceptions of whole number before and after courses leveraging this task sequence.
\end{abstract}

Keywords: variation theory; intellectual need; whole number; prospective teachers; historical number systems; number and operation; place value; base ten

\section{Introduction}


Prospective teachers (PTs) often come into mathematics content courses with knowledge of how to implement arithmetic procedures but without understanding the mathematics underlying them (e.g., Thanheiser, 2009, 2010). Further, they often see applying procedures as tantamount to understanding (Graeber, 1999). As such, they may not perceive a need to further develop their understanding of the base-ten system. If educators wish to provide PTs with opportunities to learn (Cai et al., 2017), they must develop contexts to overcome the challenges of revisiting material that PTs see as unproblematic.

To meet this need, we present a local instructional theory (LIT) (Gravemeijer \& Cobb, 2006) designed to build on prospective teachers' (PTs') incoming conceptions and to enable PTs to become aware of and make sense of the essential features of the baseten numeration system: grouping, place value, and base. The tasks are situated in various historic number systems that can serve to both to highlightand motivate understanding of the features of the base-ten numeration system. The historic contexts deprive PTs of their procedural fluency and provide a path that mimics the historic needs leading to the development of grouping, place value, and base across various number systems. We note that the systems were chosen from various cultures at various times in history and as such do not provide the development of one number system but are used to highlight various aspects of our base ten numeration system.

The $L \Pi$ is based on design principles from variation theory (e.g., Marton, Runesson, \& Tsui, 2004) and Harel's (1998; 2013) necessity principle. We argue that presenting carefully selected and sequenced tasks (Adler, 2017) to leverage variation according to the goals of the task sequence enables PTs to contrast, separate, 
generalize, and fuse properties to enrich understanding (Marton, Runesson, \& Tsui, 2004).

The LT illustrates learning opportunities for PTs. We define a learning opportunity as a situation in which students (a) engage in a context to become aware of an important feature through variation and (b) experience an intellectual need (Harel, 2013) to attend to and desire such a feature. For each step in the LIT, we share how the design provides a learning opportunity related to base ten aligned with those two features. We instantiate the trajectory with data from PTs who engaged in the task sequence and conclude by sharing pre/post data illustrating that PTs who engaged in this sequence developed richer understanding of base ten.

Our research goals are the following:

(1) Present a theoretically grounded LIT for PTs' development of base-ten understanding that integrates design principles from variation theory with intellectual need;

(2) Provide empirical evidence that this LIT has the potential to lead to PTs' growth in conceptions of base ten.

\section{Literature Review}

PTs in the United States are typically fluent with algorithms for operating on multidigit whole numbers but struggle to explain the mathematics underlying the algorithms (Ball, 1988; Ma, 1999; Simon, 1993; Thanheiser, 2009, 2010). The PTs' incoming conceptions of number limit their abilities to explain the procedures. Thanheiser (2018) found that about $80 \%$ of PTs interpret the values of the digits in a multidigit number incorrectly at least some of the time. This in turn, limits the PTs' 
abilities to make sense of the algorithms. In addition, Thanheiser (2009) showed that PTs overgeneralize the applicability of the standard algorithms beyond a base-ten context. Such overgeneralization may reflect unawareness of how the algorithm is linked with the base ten structure.

\subsection{Children's and PTs' Understanding of Base-Ten Numbers}

PTs struggle to understand the content of elementary school (Ball, 1988; Ma, 1999; Simon, 1993; Simon \& Blume, 1992; Zazkis \& Campbell, 1996) including whole number and operation (Chapman, 2007; Crespo \& Nicol, 2006; Kaasila, Pehkonen, \& Hellinen, 2010; Thanheiser, 2009, 2010). Many PTs can perform the algorithms for addition, subtraction, multiplication, and division of whole numbers (Harkness \& Thomas, 2008; Khoury \& Zazkis, 1994; Menon, 2009; Zazkis \& Khoury, 1993) but struggle when asked to explain the mathematics underlying the algorithms (Ball, 1988; Ma, 1999; Simon, 1993; Thanheiser, 2009, 2010).

For an understanding of number in our base ten numeration system we need to be able to group 10 ones into one unit of 1 ten, etc. and need to understand 10 as both 10 ones and 1 ten simultaneously thus relating the different unit types (Fuson, 1990;

Fuson et al., 1997; Hiebert \& Wearne, 1996; Steffe \& Cobb, 1988). Both children (Kamii, 1986; Valeras \& Becker, 1997) and PTs (Ross, 2001; Thanheiser, 2009, 2018) struggle identifying the meaning of the digit in the ten's place, for example, 1 in 16 as 10 ones or 1 ten rather than as a one. In addition, children and PTs often fail to connect units of different types (ones, tens, hundreds, etc.) with one another (Cobb \& Wheatley, 1988; Kamii, 1986, 1994; Thanheiser, 2009, 2018). 
Thanheiser (2009) identified four distinct conceptions PTs hold when entering their mathematics content courses in the United States (see Table 1) based on Fuson et al.'s (1997) framework for children's conceptions.

\section{Table 1}

Definition of Conceptions in the Context of the Standard Algorithm for the PTs in Thanheiser's (2009) Study

\section{Conception}

Reference units. PTs with this conception reliably conceive of the reference units for each digit and relate reference units to one another, seeing the 3 in 389 as 3 hundreds or 30 tens or 300 ones, the 8 as 8 tens or 80 ones, and the 9 as 9 ones. They can reconceive of 1 hundred as 10 tens, and so on. [correct and most sophisticated conception]

Groups of ones. PTs with this conception reliably conceive of all digits in terms of groups of ones (389 as 300 ones, 80 ones, and 9 ones) but not in terms of reference units; they do not relate reference units (e.g., 10 tens to 1 hundred). [correct conception]

Concatenated-digits plus. PTs with this conception conceive of at least one digit as an incorrect unit type at least sometimes. They struggle when relating values of the digits to one another (e.g., in 389, 3 is 300 ones but the 8 is only 8 ones). [incorrect conception]

Concatenated-digits only. PTs holding this conception conceive of all digits in terms of ones (e.g., 548 as 5 ones, 4 ones, and 8 ones). [incorrect conception]

Thanheiser (2018) showed that about $80 \%$ of U.S. PTs enter their teacher education courses with one of the concatenated-digits conceptions, reflecting incomplete understanding of essential features of base ten. PTs with such an 
understanding may explain the value of the regrouped digit in the standard U.S. algorithm (see Figure 1) incorrectly as 1 or 10 (in 14), rather than as 10 tens or 1 hundred (regrouped from the hundreds to the tens place). Thus, they may be unable to explain why the algorithm yields correct answers in base ten.

\section{7}

$\underline{-152}$

Figure 1. Subtraction problem showing regrouping

In addition, Thanheiser (2009) showed that PTs may overgeneralize the application of the standard algorithm to non-base-ten contexts, such as finding elapsed time (a mixed-base context). The literature provides impetuous for a clear learning goal: developing PTs' incomplete conceptions to arrive at the most sophisticated (referenceunits) conception of base ten.

\section{Theoretical Perspective(s)}

Students learn best when given opportunities to learn (Bransford, Brown, \& Cocking, 1999; Cai et al., 2017; National Research Council, 2001); thus, tasks and curricula should align with students' incoming conceptions, motivation to engage, and learning goals. In this paper, variation theory (e.g., Marton, et al., 2004) is paired with intellectual need (Harel, 2013) to elaborate on learning opportunities. To support PTs in providing robust learning opportunities, educators need "instructional design supporting instruction that helps students to develop their current ways of reasoning into more sophisticated ways of mathematical reasoning" (Gravemeijer, 2004, p. 106).

\subsection{Local Instructional Theories (LITs)}


LITs provide a tool for supporting teachers in providing robust learning opportunities. Such theories leverage research-based instructional design to illustrate how students may arrive at specific learning goals. An LT consists of "the description of, and rationale for, the envisioned learning route as it relates to a set of instructional activities for a specific topic" (Gravemeijer, 2004, p. 107). In contrast to a hypothetical learning trajectory, an LIT provides a travel plan that can then be adapted to a particular set of students to create a hypothetical learning trajectory. To produce a robust $L \Pi$, one needs a theory "on how to help students' construct mathematical ideas and procedures" (Gravemeijer, 2004, p. 108). Many existing LITs leverage design heuristics from Realistic Mathematics Education (e.g., Gravemeijer, 2004; Gravemeijer \& Cobb, 2006; Larsen, 2013). We add to the research literature by leveraging alternative design theories: variation theory (Gu, Huang, \& Gu, 2017; Marton \& Booth, 1997; Marton, Runesson, et al., 2004) and the necessity principle (Harel, 1998, 2013; Stylianides \& Stylianides, 2009). We begin by introducing our definition of learning then outline general theories of variation and necessity that ground our LIT.

\subsection{On Learning}

Learning is defined as experiencing, understanding, or seeing something in a different or new way (Runesson, 2006; Ryve, Larsson, \& Nilsson, 2013). Learning occurs for a person who is "capable of being simultaneously and focally aware of other aspects or more aspects of a phenomenon than was previously the case" (Marton \& Booth, 1997, p. 142).

\subsubsection{Opportunities of Learning: Variations}


In any situation, individuals focus on some aspects of a situation whereas others are in the background (Marton \& Booth, 1997). For example, understanding triangles requires awareness of many features including a figure's having three sides and being a closed polygon (e.g. Woleck, 2003). However, students may be aware of the first and not the second, as evidenced by students' identifying three-sided shapes without closure as triangles. From a variation theory lens, these students may not have experienced variation that would foreground closure as a triangle feature. A student must "experience variation in order to be able to discern a particular feature" (Holmqvist, Gustavsson, \& Wernberg, 2008, p. 111). When learners experience the variation rather than being told on what to focus, they can discern the essential features rather than have them remain unfocused in the background (Bussey, Orgill, \& Crippen, 2013; Holmqvist et al., 2008; Runesson, 2006; Schwartz \& Bransford, 1998). In the triangle example, students are unlikely to become aware of the essential feature of closure if they never interact with geometric figures that are not closed.

In general, learning situations can be thought of as analogous to jigsaw puzzles in which

the whole needs to be made more distinct, and the parts need to be found and then fitted into place, like a jigsaw puzzle that sits on the table half-finished inviting the passerby to discover more of the picture. (Marton \& Booth, 1997, p. 180) The various essential features and sub-features are referred to as dimensions of variation (Marton, Tsui, Chik, Ko, \& Lo, 2004). In learning, the various dimensions of variation must be identified and foregrounded and then pieced together (like jigsaw puzzles) to form a more complete picture. 
To build this picture, we draw on patterns of variation: separating, contrasting, generalizing, and fusing ideas (Marton, Runesson, et al., 2004). Contrasting highlights a dimension of variation by contrasting entities and nonentities. For example, in our LT, to isolate the aspect of grouping, PTs are asked to compare the Egyptian system (which is based on grouping) and the tally system (which has no grouping). Generalizing occurs through PTs' exploring varying instantiations to determine which features are specific to a given concept, such as in comparing a base-ten system to a base-twenty system (Mayan) to focus on the common feature of base. Both contrasting and generalizing fall under the larger category of separating: isolating a particular feature from a given context (Pang, Bao, \& Ki, 2017) In the previous examples, the feature of grouping and the feature of base, respectively, are separated from other features in the context. Fusion occurs when multiple critical features are accounted for simultaneously (i.e., the jigsaw pieces are now together). These experiences with variation provide the structure for learning opportunities. Thus, learning goals should align with dimensions of variation (essential features), and tasks should be designed to provide contexts in which students can experience variance and invariance along those dimensions (Coles \& Brown, 2016).

\subsubsection{Essential Features/Dimensions of Variation of the Base-Ten}

Numeration System. To leverage a variation-theory approach, we identified the essential features of the base-ten number system: grouping, place value, and base, illustrated in Table 2 (first column). Further, sub-features were identified: Values are assigned to digits depending on place; order matters; the system has a limited number of symbols; minimal grouping and zero are required. We selected various historic 
number systems on the basis of variation in the major features: tally (no grouping, no place value, no base), Egyptian (grouping, no place value, grouping by 10), Mayan (grouping, place value, base twenty), and base ten (grouping, place value, base ten). Historic number systems provide not just a context for variations but also contexts that reflect authentic intellectual need. The refinements (variations) between systems were made to meet historic needs of certainty, computation, and efficiency (expanded on in the next section).

\section{Table 2}

Number Systems With Features of Base-Ten System

\begin{tabular}{|c|c|c|c|c|}
\hline Features embedded in each system & Tally & Egyptian & Mayan & Base ten \\
\hline 1. Grouping & No & Yes & Yes $^{*}$ & Yes $^{*}$ \\
\hline 2. Place value & No & No & Yes & Yes \\
\hline $\begin{array}{l}\text { 2a. Values assigned to digits on the } \\
\text { bases of their placements }\end{array}$ & No & No & Yes & Yes \\
\hline 2b. Order matters & No & No & Yes & Yes \\
\hline 2c. Limited number of symbols & Yes & No & Yes & Yes \\
\hline 2d. Minimal grouping required & No & No & Yes & Yes \\
\hline 2e. Zero required & No & No & Yes & Yes \\
\hline 3. Base & No & 10 & 20 & 10 \\
\hline
\end{tabular}

Grouping is part of the place-value system, but it is not a mere grouping system. 


\subsection{Opportunities to Promote Intellectual Need}

To provide the impetus for students to integrate the variations into their knowledge, we leverage Harel's (2013) design principle, the necessity principle: "Students are most likely to learn when they see a need for what we intend to teach them, whereby 'need' is meant [to be] intellectual need, as opposed to social or economic need" (Harel, 1998, p. 501). Harel described intellectual need as the need to reach equilibrium by learning a new piece of knowledge. Thus, intellectual need has to do with disciplinary knowledge being created out of people's current knowledge through engagement in problematic situations conceived as such by them (Harel, 2013, p. 122).

Intellectual need is framed as an epistemological construct stemming from the mathematics field's intellectual need to create new knowledge. In this way, it is separate from motivation, which is more accurately described as a psychological construct capturing many affect-related variables. However, recently researchers have illustrated that intellectual need can promote intrinsic motivation for students and mathematicians (Hart, 2010; Kontorovich, 2015). We similarly treat intellectual need as mechanism to create motivation for students to build their understanding in a way parallel to the historic development of mathematical ideas.

Harel $(1998,2013)$ identified many intellectual needs in mathematics including (a) need for certainty, (b) need for causality, (c) need for computation, and (d) need for communication. Kontorovich and Zazkis (2016) introduced an additional need: the need for efficiency. 
The need for certainty reflects the need to determine whether a given conjecture is mathematically true. In Harel's (2013) treatment of this idea, he focused on the use of proof. In our context, we treat the need for certainty as the historic driving force for developing numeration systems that are precise rather than approximations (many).

The "need for causality is the need to explain-to determine a cause of a phenomenon, to understand what makes a phenomenon the way it is" (Harel, 2013, p. 143). In our work, we aim to perturb PTs comfort with the base-ten system to develop the need for causality. Rather than an historic reflection of intellectual need, this is a need created to specifically connect to the unique population of PTs. As mentioned previously, PTs (and children) are often efficient at performing algorithms but struggle to explaining why they yield correct answers (Ball, 1988; Ma, 1999; Simon, 1993;

Thanheiser, 2009, 2010). However, many PTs hold the belief that knowing how to apply procedures is synonymous with understanding (Graeber, 1999). PTs enter education without authentic need for causality in base-ten number systems, a need that must be developed.

The need for computation includes "determining a missing quantity from a set of quantitative constraints" (Harel, 2013, p. 131), such as determining the product of two numbers. Numeration systems naturally fill a need for computation. Harel explored this notion by addressing how the need for computation led the Babylonians to develop a positional number system with essential features such as a zero placeholder.

Harel (2013) presented the need for communication as two acts: formulating and formalizing. These acts, often reflexive in nature, capture both the act of translating language into mathematical expressions (formulating) and defining or providing a logical 
basis (formalizing). Harel notes that historically, the need for formalizing pre-dates formulating. This is reflected in our work, where the need to unambiguously convey meaning of a certain number is a driving force. However, unlike their historic counterparts, modern students are also driven to symbolize into a mathematical shorthand (formulate.)

The evolution of number systems was also driven by the need for efficiency. The need for efficiency is associated with the parsimony principle of doing a minimal amount of work to solve a given problem (Kontorovich \& Zazkis, 2016). Number systems not only provide a means for computation, but also each increase in sophistication over time (variations) increased the efficiency of computation.

To leverage the various needs, we developed tasks in which a new variation would allow for significant increases in accuracy and efficiency of computation. To leverage the need for causality, we developed tasks focused on the power of algorithms and on making PTs aware that algorithms can be performed without understanding. We posit that pairing these needs with variations provides students with (a) a situation in which they can compare and contrast to learn through variation and (b) motivation to incorporate these variations into their existing knowledge.

\section{Methods and Mode of Inquiry}

In this work, an LIT for base-ten numeration was developed through leveraging variation and necessity in using a design-based research approach (The Design-Based Research Collective, 2003) to iteratively implement and refine the tasks and accompanying theory. We share a sequence of tasks; the purpose of each task in terms 
of goals, variation, and intellectual need; and provide PTs' work illustrating how PTs typically engage with each task. We conclude with evidence that across two

implementations PTs engaged with this LIT increased their understandings of the baseten numeration system.

\subsection{Context}

Data for the LIT were collected in the context of a mathematics content course for PTs in the United States. In the United States and at this university, content courses for PTs are typically taught during undergraduate education and serve as prerequisites to enter teacher-certification programs. Content courses are divorced from pedagogical methods, which are part of teacher-certification program. The focus of these content courses was on whole number and operation. The task sequence described below was a major component of the class. The content courses were four-credit courses in a quarter system; thus, PTs met with the instructor for 40 contact hours. Participants were 36 PTs who gave consent to have their data used. Of the 36 PTs, 13 PTs (9 women and 4 men ranging in age from 21 to 64 years old) participated in a summer course and 23 PTs (16 women and 7 men ranging in age from 21 to 39 ) participated in a regular school-year course.

\subsection{Data Sources}

Data for the LIT description were drawn from PTs' work in two sections of a mathematics content course for PTs in the United States. Copies of the PTs' work were collected and scanned while they engaged in the task sequence. In this paper, we use this data to instantiate typical approaches to subtasks. 
Data for the change in conceptions were based on interviews with all PTs before and after the course. The interviews were all conducted by the first author and instructor of the course. Interview questions were chosen to identify the PTs' conceptions of number using Thanheiser's (2009) framework (Table 1) and were between 7 and 20 minutes in length, depending on the details the PTs were able to describe and the wait time they needed to give explanations. In the interviews, PTs were asked to explain regrouping in the context of adding and subtracting multidigit whole numbers (see Figure 2). To flexibly understand whole numbers, PTs need to be able to group and regroup within the base. To group and regroup, PTs must be aware of the roles of grouping, of place value, and of base ten. Ability to group and regroup based on the underlying base also enables PTs to modify the algorithms as needed for various bases. Thus, a move to reference-units provides may evidence that PTs have fused their base-ten knowledge.

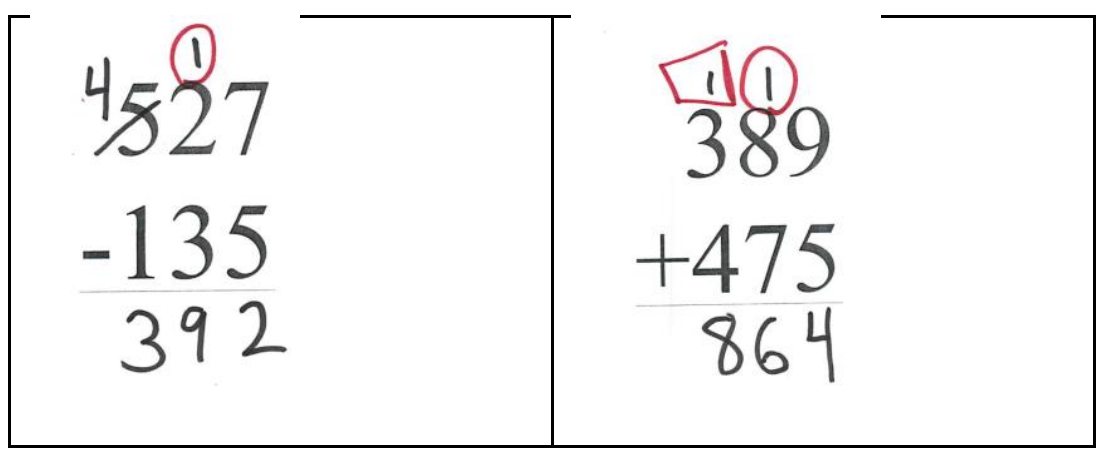

Figure 2. One PT's solutions to one subtraction problem and one addition problem

After the PTs had solved each problem, they were asked questions about various steps and why those steps were valid. Special attention was paid to the PTs' 
interpretations of regrouped ones. For a list of interview follow-up questions, see Thanheiser (2018). The interviews were videotaped and independently watched and coded by two researchers using Thanheiser's (2009) guidelines for interpreting conceptions. Agreement was $88 \%$ (the disagreements were resolved through discussion). Both groups of PTs experienced the same sequence of tasks exposing them to alternative number systems described below.

\subsection{Task Sequence}

The task sequence incorporates the base-ten system and three historic numeration systems chosen to differ along the three major dimensions of variation: grouping, place value, and base (see Table 2). The historic systems are: the tally system with none of the base-ten features (no grouping, no place value, no base), the Egyptian system (grouping, no place value, grouping by 10), and the Mayan system (grouping, place value, base twenty). These systems are contrasted with the base-ten system (grouping, place value, base ten) (see Table 3). In the LIT, we describe each activity, show artifacts from class, discuss the variations the systems afford, and describe the motivation for PTs to attend to each feature through the lens of intellectual need.

Table 3

Variation Along the Major Dimensions of Variation

\begin{tabular}{lcccc}
\hline Features in each system & Tally & Egyptian & Mayan & Base \\
& & & & ten \\
\hline Grouping & No & Yes & Yes $^{*}$ & Yes $^{*}$ \\
\hline Place value & No & No & Yes & Yes \\
\hline
\end{tabular}


No

Base ten

No (Grouping by 10 but not

No $\quad$ Yes

base)

"Grouping is part of the place-value system, but it is not a mere grouping system.

\section{Local Instructional Theory}

In this section, we describe our LIT for base-ten numeration. An overview of the goals in the sequence with the accompanying intellectual need and variation is followed by a detailed description of each goal, the tasks illustrated with PTs' work engaging with the task, and the instructional rationale. We close this section by discussing the last goal, fusion.

\subsection{Local Instructional Theory for Developing Understanding of Base Ten}

The general LIT is focused on three features: grouping structure, place value, and base ten, and the fusion of these features. The stages are as follows:

Goal 1. Becoming Aware of a Grouping Structure

- Developing intellectual need for certainty and computation in non-grouped system (tally)

- Contrasting a non-grouped system (tally) with grouped systems (studentgenerated)

- Developing intellectual need for communication (symbolizing studentgenerated groupings)

- Generalizing grouping (student-generated, Egyptian)

Goal 2. Becoming Aware of a Place-Value Structure 
Goal 2(A) Becoming Aware of Value on the Bases of Placement and Order

- Generalizing and contrasting across numbers not ordered consistently (Egyptian)

- Contrasting a non-order-dependent system (Egyptian) and orderdependent system (base ten)

Goal 2(B) Becoming Aware of Repetition of Finite Symbols

- Contrasting a system without finite symbols (Egyptian) and a system with finite symbols (base ten)

Goal 2(C) Becoming Aware of Minimal Grouping

- Generalizing and contrasting across numbers grouped in various ways (Egyptian)

- Contrasting a non-minimally grouped system (Egyptian) and a minimally grouped system (base ten)

Goal 2(D) Becoming Aware of the Role of Zero in a Place-Value Structure

- Contrasting a system without zero (Egyptian) and a system with zero (base ten)

Goal 2(F) Fusion of Place-Value Structure

- Developing Intellectual Need for Efficiency (Computing in inefficient placevalue-free system)

- Contrasting non-place-value system (Egyptian) and place-value system (Mayan)

Goal 3 Becoming Aware of a Base-Ten Multiplicative Structure

- Contrasting base-ten system with a non-base-ten system (Mayan) 
- Developing Intellectual Need for certainty for values of place-value system (Mayan)

- Developing Intellectual Need for Causality (Engaging in computations without understanding)

Goal 4 Fusion

- Coordinating the essential features in tandem (Returning to base-ten tasks)

\subsection{Goal 1 Becoming Aware of a Grouping Structure}

PTs' incoming conceptions (mostly concatenated-digits plus or concatenateddigits only) reflect that many conceive of the digits in a number as representing ones rather than groups of ones or groups of different sizes. PTs typically perform calculations but do not make sense of them. When at the beginning of the course they are asked to explain regrouping in the standard algorithms for addition and subtraction and are typically unable to do so (Thanheiser, 2018), they recognize that the mathematics of the algorithms can be explained but they are not able to explain them (Thanheiser, Philipp, Fasteen, Strand, \& Mills, 2013). This recognition lays the foundation for the need for causality.

Our first goal for the LIT is to provide students learning opportunities to develop awareness of grouping through placing them in a situation in which (a) they see a system that has no grouping to allow for contrast with base ten, (b) an intellectual need for grouping is developed via a need for computation and certainty, and (c) they generalize grouping structure across various systems. We illustrate how this awareness can be developed through a specific task: The Tally Activity. 
5.2.1 The Tally Activity. The PTs were introduced to the idea that all number systems have one thing in common: Each system has a symbol for 1 (tally) (May, 1970). Beyond that, number systems differ in their features. The PTs were then given (a) the following context: An ancient farm ouner who lived in a time when only tallies existed recorded how many cows he had by recording one tally for each cow he saw and (b) the Tally Activity shown in Figure 3.

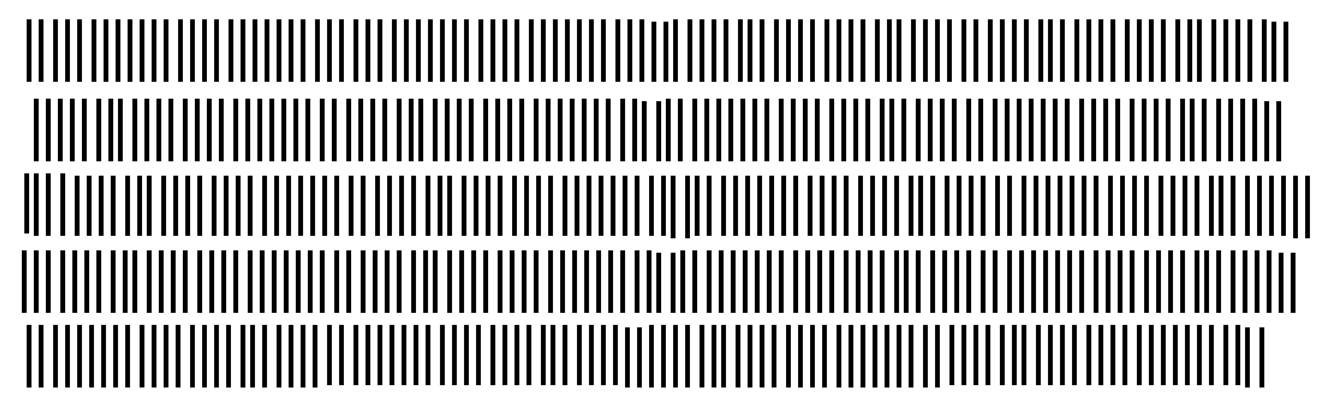

The above marks how many cows I own.

1. In our base ten system how many cows is that?

2. How did you find the answer (Please be explicit about this)? What did you do? First I did ...

3. Are you sure you have the correct number? How do you know?

4. What is the point of this activity?

Figure 3. The Tally Activity

The approximately 500 tallies (see Figure 3 ) are purposefully misaligned to necessitate counting all tallies (rather than grouping by rows or using a comparable strategy). The PTs were asked to translate the number of cows the farmer owned from the tally system to the base-ten number system. 
Counting each individual tally leads to difficulty in computation and uncertain

results. To meet this need for computation, PTs typically group 5, 10, or 20 tallies into a group and mark the groups (for example by circling). The PTs then count those groups; two examples are shown in Figures $4 a$ and $4 b$.

Figure 4a. A PT's grouping by 10 s in the Tally Activity

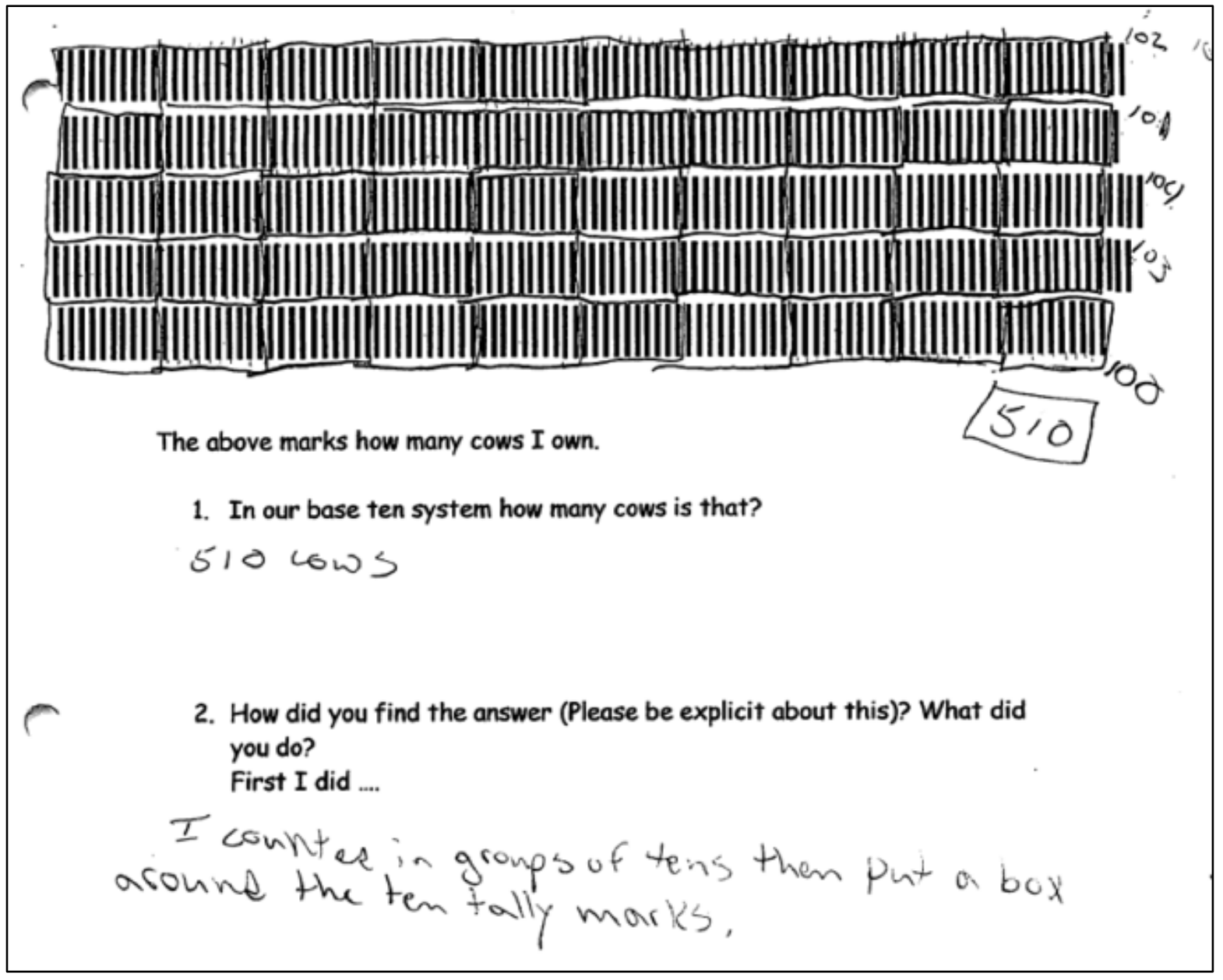


Figure $4 b$. PT's grouping by 5 s and 10 s in Tally Activity

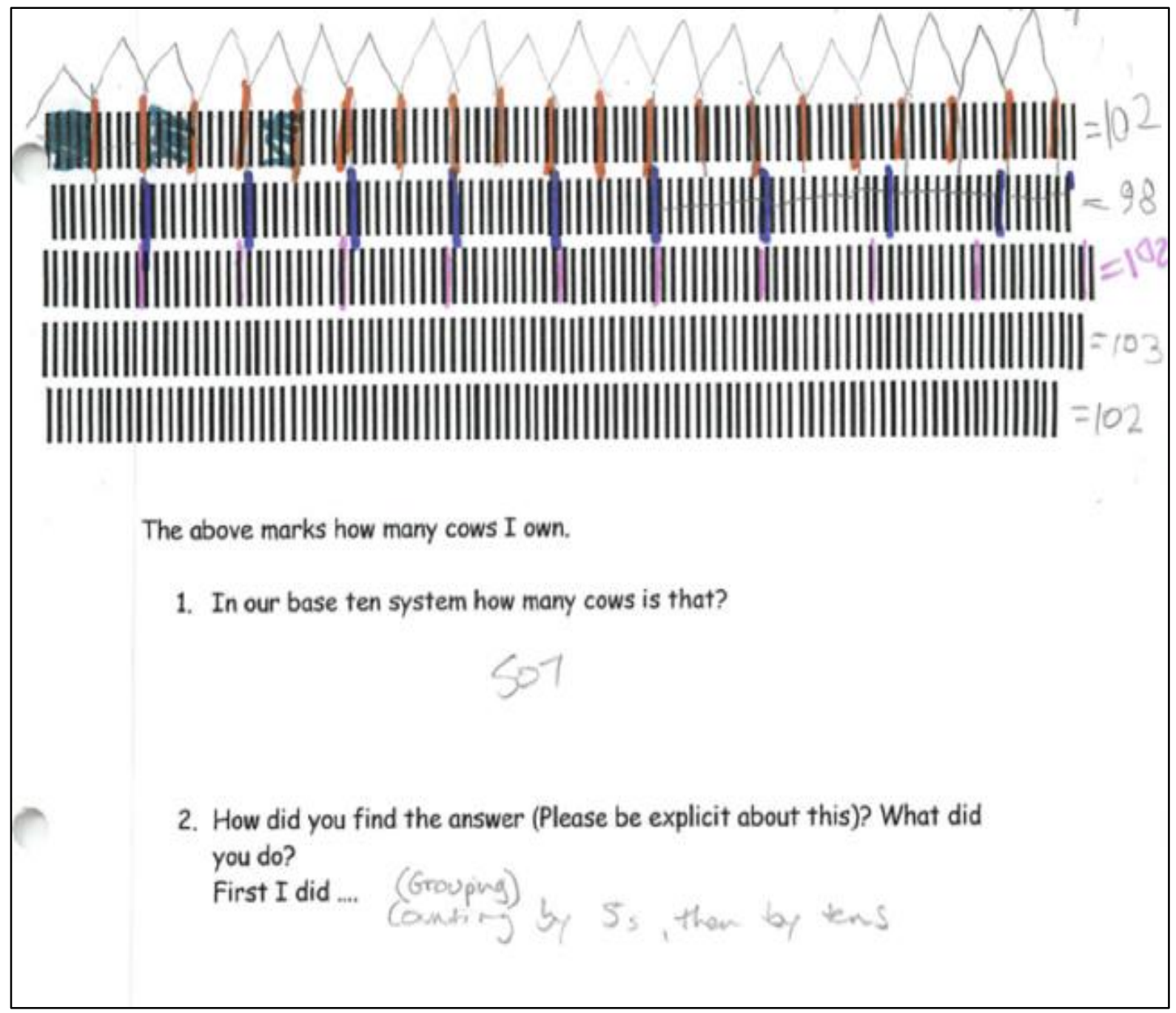

Even using the computational approach, PTs typically arrived at a range of answers from 501 to 512 cows. These differences tap into PTs' intellectual need for certainty. The PTs wanted to know which answer is correct. The difficulty in determining the exact number of cows represented by so many tallies led the PTs to recognize that the tally system is inefficient for recording large numbers. Even with grouping, counting is cumbersome. This inefficiency for representing large numbers combined with the uncertainty of accurately determining the number of many tallies 
creates the need for a better system to quantify, therefore tapping into the students' need to compute and ultimately quantify more efficiently to get accurate answers.

The PTs' need for certainty and computation led them to focus on the dimension of grouping (Feature 1, Table 2), which is lacking in the tally system. The PTs often initially invent their own symbols to represent numbers (see Figure 5 for an example) and then discuss standardization of such symbols in addressing the need for communication.

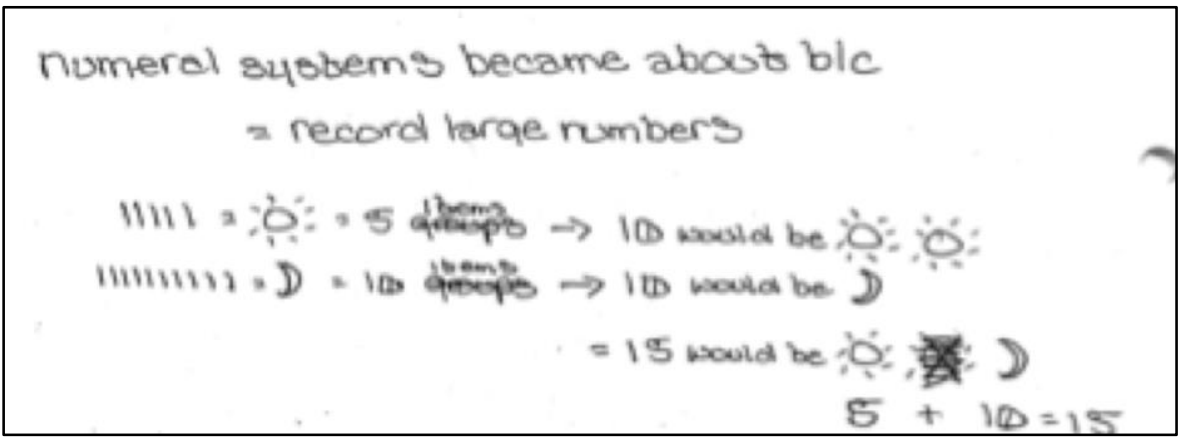

Figure 5. A PT's invention of new symbols for groups of tallies

5.2.2 Instructional Rationale. The goals for the Tally Activity are to necessitate and thus highlight the feature of grouping ones into groups of larger size and then represent those new groups with new symbols. After the PTs isolated these features, they were introduced to the Egyptian System, which incorporates such grouping and symbolizing and is aligned with the groups-of-ones conception from Thanheiser's (2009) framework. The PTs can generalize the idea of grouping across their generated systems with the Egyptian system (which also provides the context for the next goal in the LIT.) 
Because the tally system is the first system on which the PTs work, no explicit comparison or contrast is made between it and other number systems. However, students conclude that the tally system lacks the feature of grouping (Feature 1), forming the basis for introducing the next system, the Egyptian system.

\subsection{Goal 2 Becoming Aware of a Place-Value Structure}

At this point in the LT, students have become aware of the feature of grouping through engaging with a system without grouping, generating a grouping system, and then generalizing grouping to new systems such as the Egyptian system. The next dimension of variation in number systems is place-value structure. Just as a nongrouped system allows for developing a need for and identifying a grouping structure, a non-place-value system can provide a contrast to and develop a need for a place-value system.

Place-value structure has a number of sub-features: order dependency, minimal grouping, and the role of zero. PTs can become aware of these features via contrasting a non-place-value system with base ten. When PTs are prompted to discuss numbers, they can develop an intellectual need for communication (i.e., to remove ambiguity about the numbers). When students are prompted to compute, they can develop an intellectual need for efficiency (when computations without place-value structure become difficult.) Students can then attend to these features in tandem as components of place value (fusion), ultimately contrasting base ten (a system with all the place-value features) to the Egyptian system (a system without some features.) We next outline a task that can provide students with opportunities to learn place value: The Egyptian Activity. 
5.3.1 The Egyptian Activity. The goals for the Egyptian activity are to highlight the advantages of a grouping system (Feature 1 , Table 2 ) as compared to a tally system and to create a need for a place-value system (Feature 2, Table 2). The PTs are introduced to the Egyptian numeration system (see Figure 6) as an historical grouping system. They are then asked to convert between the base-ten and the Egyptian systems (see Figures 7a and 7b).

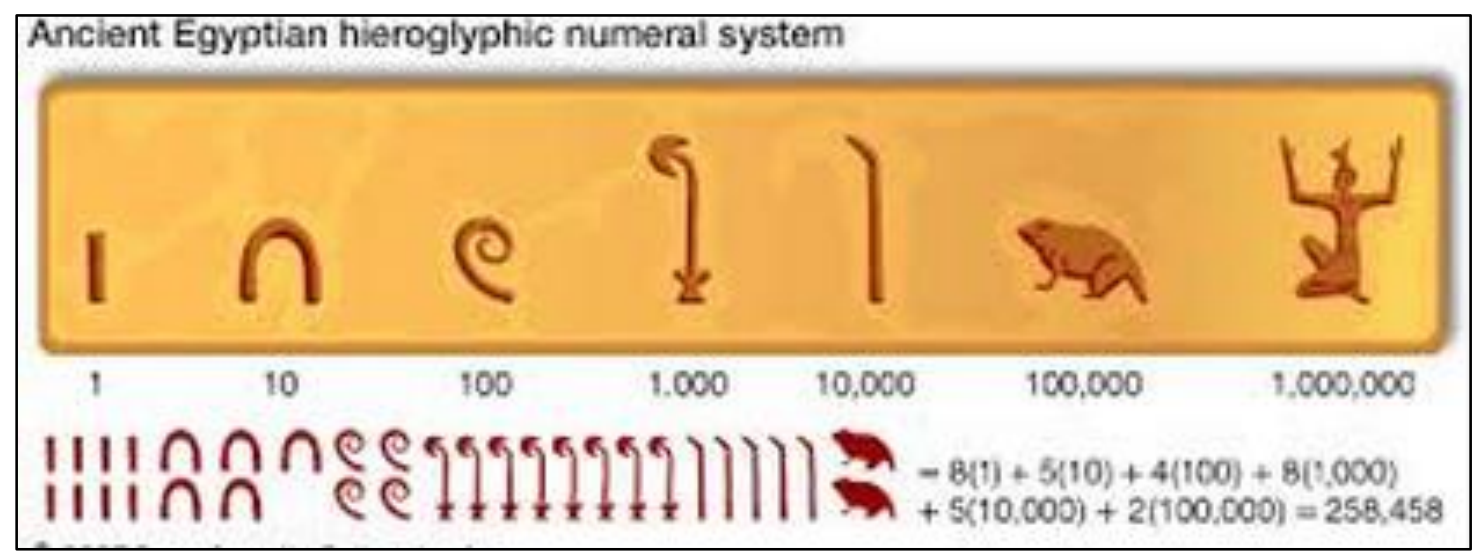

Figure 6. Egyptian numbers retrieved from https://www.britannica.com/topic/numeral 


\section{Can you figure out the Egyptian number system?}

$\|\cap \Omega\|\|\|_{\text {is one way the Egyptians wrote the number } 26 .}$

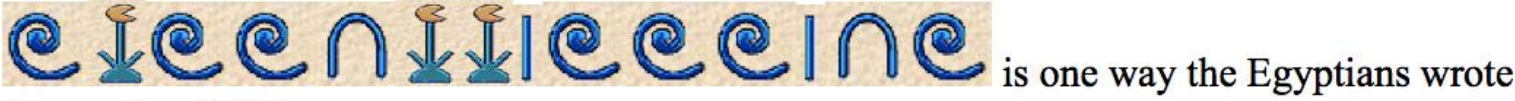

the number 3,722 .

1. How do you think the Egyptians wrote the number 37 ?

2. How do you think the Egyptians wrote the number 241?

3. How do you think the Egyptians write the number 4,508?

4. On this sheet you thought about the values for the various Egyptian symbols. What might be the value of the next symbol and what might it look like?

\begin{tabular}{|l|l|l|l|l|l|}
\hline $\begin{array}{l}\text { Egyptian } \\
\text { Symbol }\end{array}$ & 1 & $\bigcap$ & $\bigcirc$ & $\sqrt[d]{ }$ & \\
\hline Value & & & & & \\
\hline
\end{tabular}

Figure 7a. Egyptian Worksheet 1

\section{Egyptian Numbers}

$\|\mathrm{e}\|$ is one way the Egyptians wrote the number 40,100 .

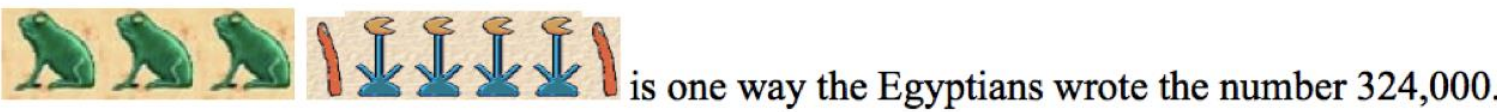

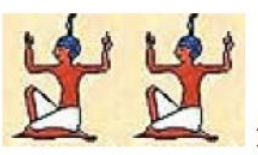

is one way the Egyptians wrote the number 2,000,000.

1. How do you think the Egyptians wrote the number 55,000 ?

2. How do you think the Egyptians wrote the number 200,000?

3. How do you think the Egyptians wrote the number $3,460,000$ ?

Figure 7b. Egyptian Worksheet 2 
The Egyptians used various symbols for groups of powers of ten (ones, tens, hundreds, etc.). The order of these symbols is insignificant; an arch represents 10 no matter where it is written in a number. Although most Egyptian numeration is written largest to smallest for ease of reading, it is not an essential feature of the Egyptian system. We presented the PTs with Egyptian numerals in mixed order (not ordered from largest to smallest). Through working with these unordered numbers, students become aware that order is not standardized in the Egyptian grouping system (Feature 2a, Table 2).

Students were presented with the first few symbols of the Egyptian system and were asked to produce the next symbol and identify what quantity it would represent (Worksheet 1). This question was designed to encourage grouping repeatedly by 10 (Feature 1, Table 2) and to incite discussion about the need for a new symbol for each subsequent group (Feature 2c, Table 2). Grouping repeatedly by 10 is not easily visible in the base-ten system because the words ones, tens, hundreds do not explicate the relationship among adjacent place values. The Egyptian system can be leveraged to highlight this repeated grouping by 10 .

Asking PTs to represent 4508 with the Egyptian symbols (Worksheet 1) created a situation for students to explicitly contrast the base-ten representation with the Egyptian. Students then discussed whether one needs to represent the zero tens (Feature 2c, Table 2), developing awareness of the role of a zero in a place-value system. They came to recognize that zero serves a communication role in number systems, tapping into the intellectual need for communication. 
Finally, we presented the PTs with numbers written in minimal grouping and nonminimal grouping (Feature 2d, Table 2) in the Egyptian system so that students could contrast numbers in the Egyptian system to become aware of this permissible variation. PTs also contrasted with base ten wherein this variation is not permissible. Seeing numbers with mixed order and non-minimal grouping taps further into students' intellectual need for communication. The multiple representations of the same numeral cause uncertainty about what numbers are used and make communication ambiguous. After familiarizing themselves with the Egyptian system and discussing the features listed above, PTs were asked to perform multiplication in this system (see Figure 8).

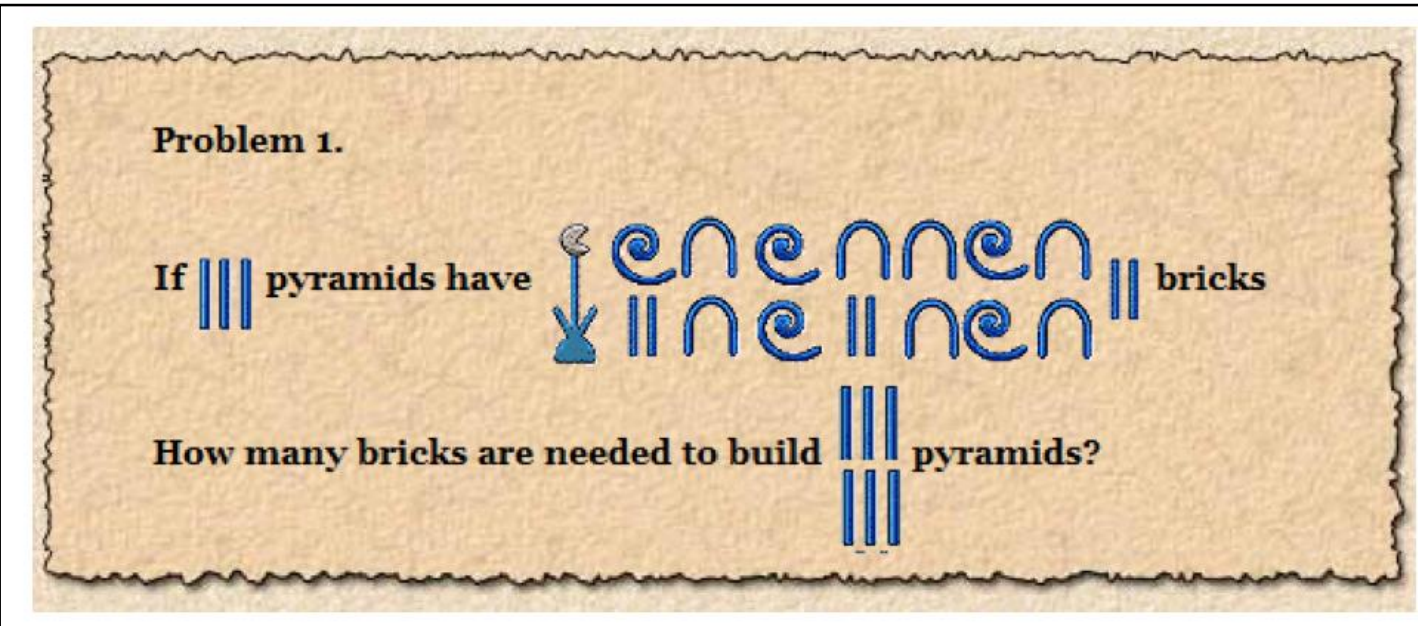

Do the calculation by staying within the Egyptian Symbols (you are an Egyptian not familiar with our number system. SHOW YOUR WORK.

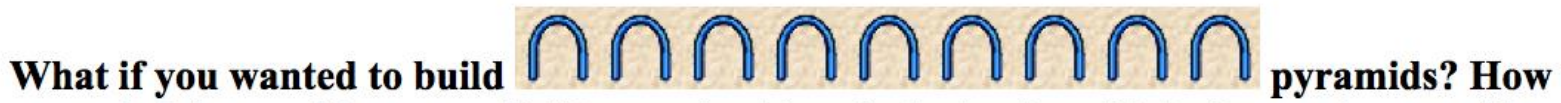
many bricks would you need? [Do not do this calculation but think about what would make it difficult to do]

Figure 8. Egyptian multiplication task. Task adapted from http://discoveringegypt.com/egyptian-hieroglyphic-writing/egyptian-mathematicsnumbers-hieroglyphs/ancient-egyptian-mathematics-problems-for-12-16-year-olds/ 
Although one can multiply in the Egyptian system (with repeated addition and repeated regrouping or doubling and halving), clearly the operations are quite cumbersome in this system (see Figure 9 for an example). PTs commented, for example, "This would result in a profane amount of symbols," and "It would be difficult," as well as "It would be really cumbersome," when asked to multiply a number by 30 . The intellectual need for efficiency becomes a driving force to motivate the need for a different kind of number system in which calculations can be made efficiently. 


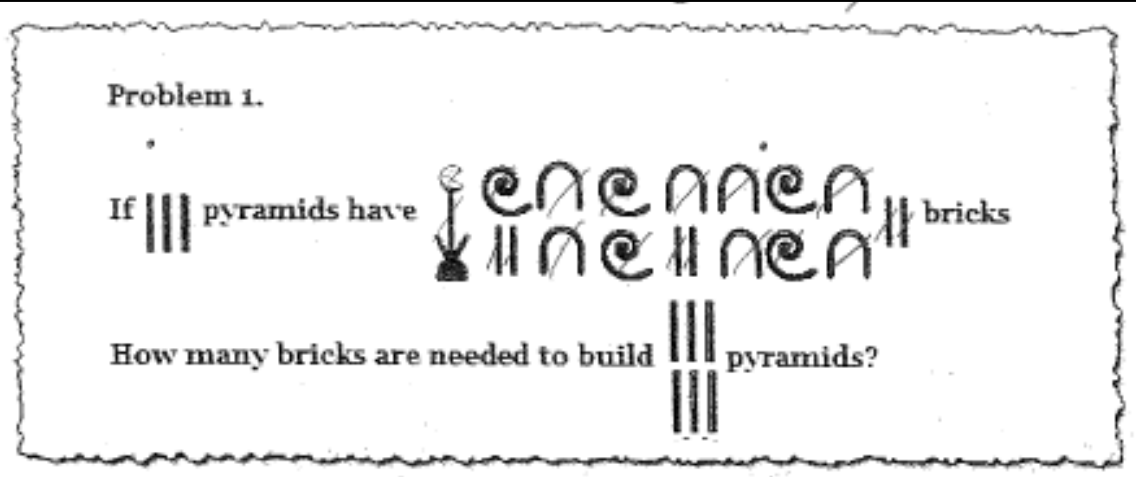

Do the calculation by staying within the Egyptian Symbols (you are an Egyptian not familiar with our number system. SHOW YOUR WORK.

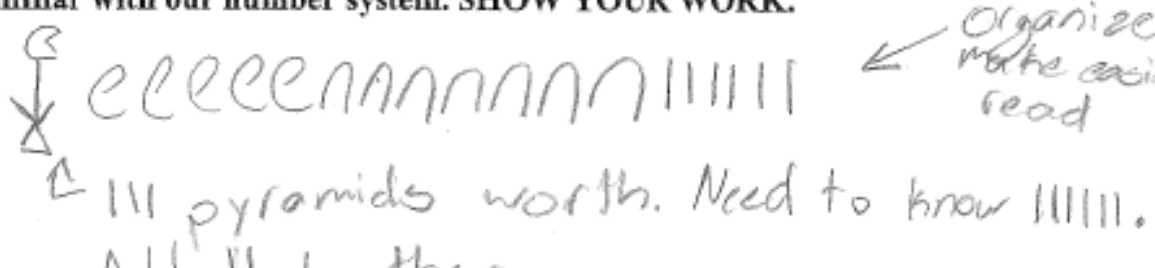

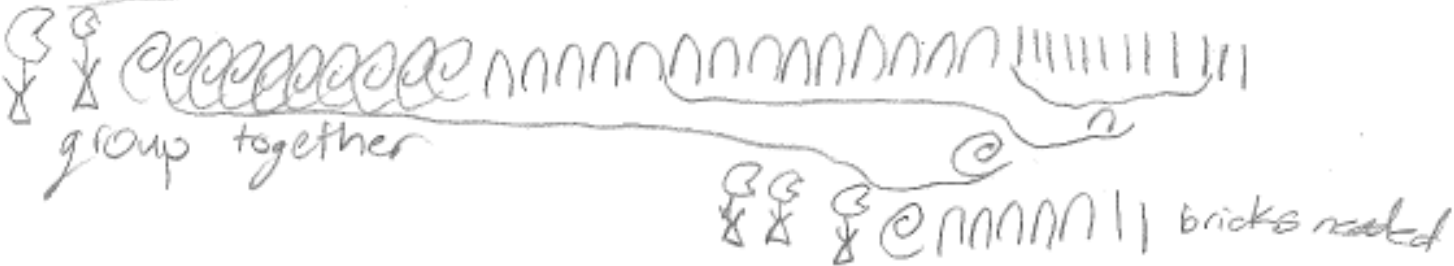
What if you wanted to build $\mathrm{M} \cap \mathrm{M} \cap \mathrm{M} \cap$ pyramids? How many bricks would you need? [Do not do this calculation but think about what would make it difficult to do]
Too many
symbols to
- keep track
together,
Yan'd need
to maltiply
th of then graye
the number by 30

Figure 9. One PTs response to the Egyptian multiplication task. Task adapted from http://discoveringegypt.com/egyptian-hieroglyphic-writing/egyptian-mathematicsnumbers-hieroglyphs/ancient-egyptian-mathematics-problems-for-12-16-year-olds/ 
5.3.2 Instructional Rationale. Our goal for working with the Egyptian system after the tally system was to highlight the power of grouping (Feature 1, Table 2) for representing large numbers succinctly. In the Egyptian system, one groups by 10 , which is highlighted (and thus made visible) and then held constant with the base-ten system (Feature 3, Table 2). Limitations of the Egyptian system discussed include (a) many symbols may be needed to represent some numbers (Feature 2c, Table 2); (b) the same number can be represented in various ways (not ordered, not in minimal grouping) (Features $2 b$ and $2 d$, Table 2); (c) zero is not needed (Feature 2e, Table 2); (d) calculations are cumbersome. These limitations show the need for a different system.

Our final goal in having PTs become aware of place value is fusion, which occurs when PTs can consider place value as a single entity. To engage students in this treatment, PTs can be placed in a situation in which they contrast between a non-placevalue system and a place-value system and generalize across different place-value systems. We introduce the Mayan Activity to provide a contrasting system to the Egyptian, then to bring attention to the next essential feature: multiplicative basestructure.

\subsection{Goal 3. Becoming Aware of a Base-Ten Multiplicative Structure}

Awareness of a base-ten multiplicative structure is built upon understanding place value, then leveraging this understanding to make sense of a particular structure: multiplicative base structure. PTs' attention can be drawn to base structure by exposing the PTs to a system with an unfamiliar base so that they contrast the base-ten system with that alternative system. We also see this component of the LIT as motivating sense 
making by developing an intellectual need for causality of the base-ten system by engaging PTs in efforts to make sense of a parallel system. We outline one such task, the Mayan Activity, which serves to bridge place-value fusion and awareness of baseten multiplicative structure.

5.4.1 The Mayan Activity. The goal of this activity is to highlight place value (Feature 2, Table 2) and the 10 to 1 ratio between the values of adjacent digits in base ten (Feature 3, Table1). The PTs are introduced to the Mayan system (base twenty: 20 to 1 ratio between the values of adjacent digits) as one of the historical number systems that incorporated both grouping and place value (requiring a fused idea of place value.) The PTs are provided with the first 30 numbers (see Figure 10), and they familiarize themselves with the Mayan number system by converting between base-ten numbers and Mayan numbers within the first two place values (activity modified from Overbay \& Brod, 2007). In this situation, PTs can contrast the grouping structures of base ten and Mayan (base twenty) numbers. The PTs see that a unit with a zero represents 20 in the Mayan system. After the PTs have converted the first 30 numbers, they are asked what a unit with 2 zeros $(400)$ and a unit with 6 zeros $\left(64 \times 10^{6}\right)$ represent (see Figure 11). Typically PTs struggle to identify these values (Thanheiser, 2014) because they are unaware of the function of the base (either they do not attend to it or they overgeneralize base ten). In Thanheiser's study, the most common interpretation of a unit with 2 zeros was 200 (because a unit with 1 zero represents 20 and a zero was incorrectly appended to that 20), and the most common interpretation of a unit with 6 zeroes was 20,000,000 (same line of reasoning). Other responses for a unit with 2 zeros typically include 400 (two arguments given below), 100 (a unit appended with 2 
zeros was incorrectly interpreted as 100), 30 (each place value was incorrectly interpreted as 10 and 3 tens were added, one for each of the three symbols), and 40 (adding $20+20$ ). Discussing these varied solutions tapped into PTs' intellectual needs for certainty: They wanted to know the correct answer. This experience led the PTs to compare arguments, which ultimately focused their attention on the base.

PTs developed two types of correct arguments to make sense of this task, first completely filling every place and thus determining at what value one would "spill over" to the next place $(20,400$, etc.). This argument aligns with a groups-of-ones conception. In their second argument, they used the multiplicative relationship between adjacent places as $\times 20$, so the first place represents ones, the second 20 , the third $20 \times 20=$ 400, and so on. This argument aligns with a reference-units conception. Identifying the value of a unit with a certain number of zeros highlights the ratio between adjacent values as 20 to 1 (contrasting with the base-ten 10 to 1 ratio) (Feature 3, Table 2).

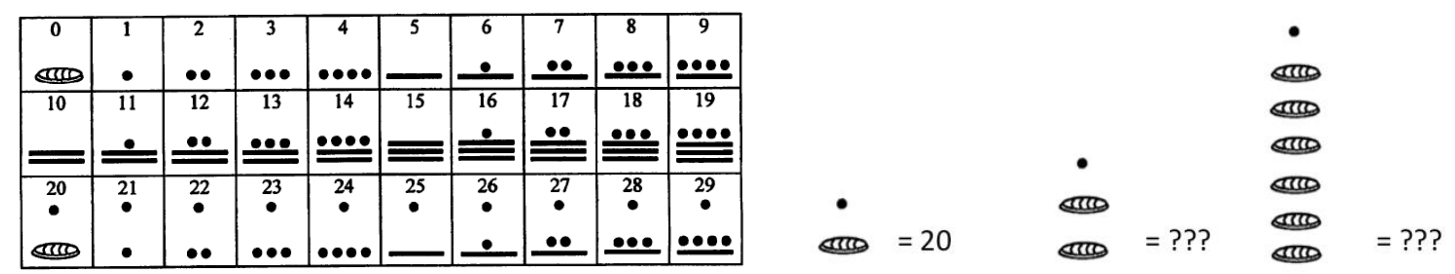

Figure 10. Chart of the first 29 Mayan

Figure 11. Task to identify a unit with 2 and numerals 6 zeros, respectively

Next the PTs were asked to create addition and subtraction algorithms in the Mayan system, using the base to regroup between place values. This activity highlights 
the power of place value and algorithms. The 20 -to- 1 structure between place values provides the structure for regrouping 20 in a lower place to 1 in the next higher place. Because PTs could not intuitively read Mayan numbers, this system demonstrates well how one can work with an algorithm on numbers one does not quite understand or know and enables PTs to relate to their abilities to use but not explain base-ten algorithms at the beginning of the term. Working in the Mayan system illustrates clearly that one can apply algorithms to numbers not (yet) understood, promoting a need for causality. PTs can combine within each place value when adding and then regroup (see Figure 12a), iteratively regroup (see Figure 12b), or simulate the U.S. standard algorithms (see Figure 11c). In any case PTs need not be explicitly aware of the values with which they are working.

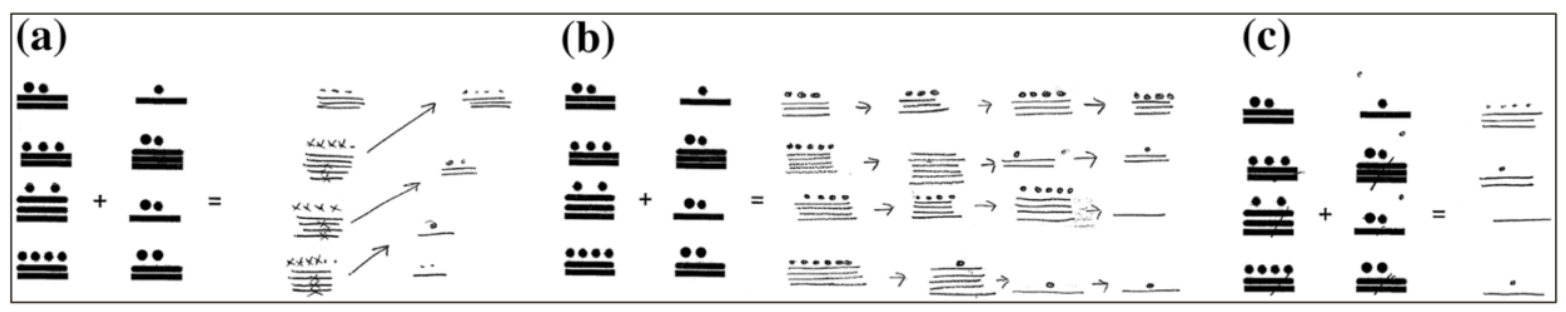

(a) Adding all in each place, then regrouping

\begin{tabular}{rrr}
$4 \quad 8 \quad 9$ & 489 \\
$+3 \quad 7$ & 5 & +375 \\
\hline$[7][15]$ & {$[14]$} & 14 \\
$8 \quad 6 \quad 4$ & 150 \\
& & 700 \\
\hline
\end{tabular}

(c) Modeling the U.S. standard algorithm

489 $+375$ 864

Figure 12. Three ways to add numbers in the Mayan number system and the baseten system. Note that the numbers added in the two systems are different 
5.4.2 Instructional Rationale. The goal for PTs' working with the Mayan system is to highlight the power of place-value systems (Feature 2, Table 2) as compared to nonplace-value systems (such as the Egyptian system) in representing large numbers with a limited number of symbols (Feature 2c, Table 2) and in computing within the system. In addition, work with the Mayan system highlights the mostly hidden feature of the base-ten system, namely that groupings are based on groups of 10 (Feature 3, Table 2). The Mayan system is a base system like base ten, highlighting the multiplicative structure, but it has one significant difference: grouping by 20 , which serves to highlight grouping by 10 in base ten. This task addresses the overgeneralization of the standard algorithms to contexts other than base ten by explicating the meaning of the regrouped digit in relation to the base.

\subsection{Goal 4. Fusion}

The last goal for the trajectory is for PTs to fuse the various features of which they have become aware by moving back to base ten. We explored whether this fusion occurred by returning to tasks from the conception survey in which students use baseten algorithms and explain the meanings underlying the steps.

\section{Discussing of Variation in the LIT and Task Sequence}

After PTs worked with more than one system, they compared and contrasted across systems. Comparing and contrasting the differing systems enables PTs to identify similarities and differences (dimensions of variation) among the number systems, to explicate aspects of each, especially base ten (identify pieces of the jigsaw 
puzzle), and thus to build better understanding of base ten (put the puzzle pieces together).

The power of this task sequence derives from two combined features of the tasks: (a) aspects of the base-ten system that are not easily observable without moving beyond the base-ten system are made explicitly visible, and (b) the need for more accurate/efficient/better numerations systems are developed to motivation integration of the new features into understanding of the base-ten system. Using a tally system illuminates grouping (Feature 1, Table 2) and highlights the need because no grouping is available within that system. Using the Egyptian system (a grouping system) highlights several aspects of the place-value system (Features $2 a-2 e$ ) and creates a need for a more concise numeration system to limit the number of symbols needed and to allow for efficient computations. Using the Mayan system (a place-value system) highlights grouping by 10 versus other groupings because the Mayans grouped by 20 (Feature 3, Table 2). The features highlighted as different from base ten in each system in each task (to raise awareness of the features' importance in base ten) are illustrated in Table 4.

Table 4.

Features Highlighted in Each Activity and in their comparisons.

Features Highlighted in each of the Tally Egyptian Mayan activities and in their comparisons

1 Grouping

2 Place value

2a Value dependent on symbol placement
X

X

X

X 


\section{$2 b$ Order \\ $2 c$ Limited number of symbols \\ 2d Minimal grouping required \\ 2e Need for zero \\ 3. Base ten}

$\mathrm{X}$

$\mathrm{X}$

$\mathrm{X}$

$\mathrm{X}$

The variations emphasized between the tally system and place-value systems are that the tally system has none of the features; thus, recording large numbers is cumbersome prompting an intellectual need for certainty, communication, computation, causality, and efficiency. In completing the Tally Activity, PTs experienced difficulty in keeping track of many tallies and began grouping them.

The variations emphasized between the Egyptian system and the base-ten place-value system are that in the Egyptian system symbol location is irrelevant (Feature 2a, Table 2), symbol order is irrelevant (feature $2 \mathrm{~b}$, Table 2), the system has infinitely many symbols (Feature $2 \mathrm{c}$, Table 2), grouping is not required to be minimal (Feature 2d, Table 2), and the system has no need for zero (Feature 2e, Table 2). The fact that operations are quite cumbersome in the Egyptian system relates to PTs' intellectual needs for certainty, communication, and efficiency and thus served as a motivator for place-value systems. In the Egyptian Activity, PTs noticed that the place of the symbols does not matter (Feature 2a, Table 2); however, for ease of reading and writing numbers, the PTs (like the Egyptians) ordered the symbols from largest to smallest, leading them to notice that the base-ten system has the same underlying grouping structure (ones, tens, hundreds, etc.) as the Egyptian system (Feature 3, Table 2). When asked to perform operations (such as multiplication) in the Egyptian 
system, PTs realized how awkward such operations are in non-minimal grouping systems. Thus, this activity highlighted the advantages of grouping systems (i.e., recording large numbers, values of symbols are fixed) and their limitations (cumbersome for calculations).

The variation emphasized between the Mayan system and the base-ten place value system is the explication of the underlying base (20 vs, 10) (Feature 3 , Table 2) and the relationship between adjacent unit types as $\times 20$ (in the Mayan system) and x10 (in the base-ten place-value system). The power of this task derives from the fact that conceptions that are not easily observable in the base-ten place-value system become visible and can be examined by the PTs (i.e., appending zeros in base ten vs. using zeros in conjunction with powers of 20 in the Mayan system). This activity can then prompt PTs to consider why procedures such as appending zeros can be used in placevalue systems and what they mean. Along the same lines, regrouping in adding and subtracting numbers can be explained, and the fact that one regroups between a group of larger size and groups of the next smaller size is explicated (it is not hidden behind a procedure). PTs often quite naturally invent sense-making algorithms in the context of the Mayan numbers and thus experience sense making connected to arithmetic operations.

\section{PTs' Conceptions}

In this section, we provide evidence that PTs who engaged in a task sequence aligned with the LIT developed richer conceptions of base-ten numeration. Most (31 of 36) PTs developed one of the correct conceptions of number (reference-units or groupsof-ones) by the end of the course with 26 having the most significant sophisticated 
conception (see Table 5). To hold the reference-units conceptions, PTs must understand and be aware of all three aspects of base ten noted in Table 1, namely, grouping, place value, and base ten. For example, when adding multi-digit whole numbers, students with correct conceptions could explain a regrouped one (in the tens place) as both a group of one ten, and ten ones. An exact McNemar's test determined that there was a significant difference in the number students who moved to a reference-units conception by the end of the course (24 of 26 students who could move to a reference-units) compared the expected number of PTs moving between categories due to chance, $p<001$. In fact, this change was quite robust as no students went from a reference-unit conception to non-reference unit conceptions. Overwhelmingly, the PTs moved to a robust understanding of base ten.

\section{Table 5}

PTs' Conceptions of Number After the Course Related to Their Conceptions Before the Course.

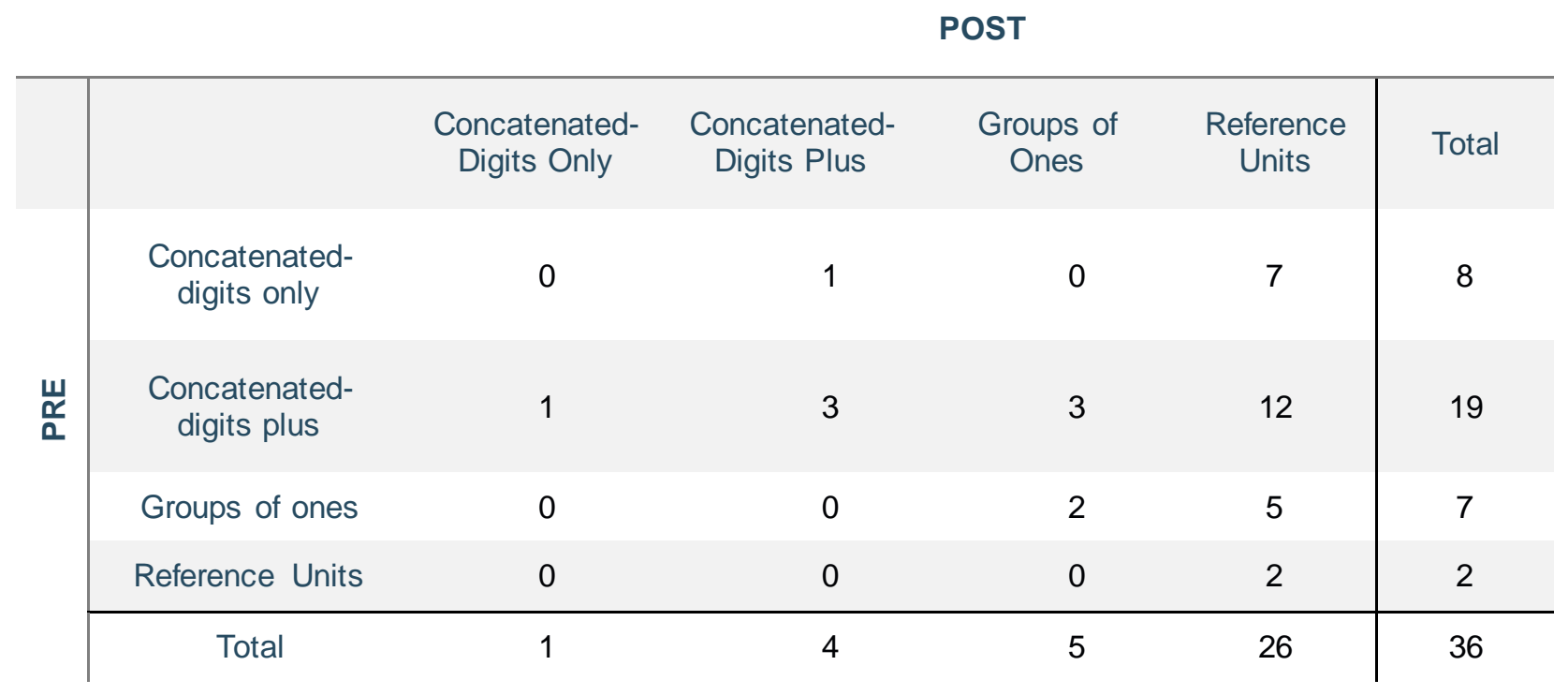




\section{Discussion and Conclusion}

In this paper, we illustrated how variation theory (Marton et al., 2004) and intellectual need (Harel, 2013) could serve complementary roles in an LIT. Additionally, we provided an LIT that may support the specific needs of PTs coming to understand the base-ten system. We created a corresponding sequence of tasks to (a) create a need for more sophisticated numeration systems and (b) highlight the features of the base-ten number system via engagement with varying numeration systems. Each numeration system in the sequence differed from the prior task by one (or several) features of the base-ten system. Each numeration system was introduced as a solution to meet a need created by the previous task. As such, PTs understood not only the nature of the number systems but also the need for the development of new systems when the older ones were inadequate. The historic intellectual need was recreated for the PTs to motivate their own learning and assimilation of new knowledge about number systems. The combination of the two factors, intellectual need and variation theory, served a powerful role in task design focused on learning opportunity. We conjecture that these design principles could inform the development of other LITs linked to core content areas in mathematics.

Throughout the LIT, we relied on the need for certainty, computation, communication, efficiency, and causality. For learning to occur, students must both attend to varying situations and be motivated to integrate new understandings with their previous knowledge. We paired our LT with pre/post data from two classes of PTs that engaged with the outlined task sequence. The LIT was a major component of the 
course and as such likely contributed to the change in conceptions. Most students

moved from being unable to explain the mathematics underlying U.S. standard

algorithms to developing rich conceptions of base ten to accurately account for the roles of grouping (and regrouping), place value, and the base ten.

When addressing the needs of PTs, educators must problematize the base-ten system so that PTs can engage in genuine learning opportunities. An LIT provides one mechanism for moving from theory and research to results that are useful for practice (Cai et al., 2017). In that sense, the LIT in this paper is both a research contribution, but also immediately usable by practitioners. Further, we also contribute a model for designbased research to integrate learning opportunities (in terms of patterns of variation) with motivation (in terms of intellectual need).

\section{References}

Adler, J. (2017). Foreword. In R. Huang \& Y. Li (Eds.), Teaching and learning mathematics through variation: Confucian heritage meets western theories (pp. xi-xiv). Rotterdam, The Netherlands: SensePublishers.

Ball, D. (1988). Knowledge and reasoning in mathematical pedagogy: Examining what prospective teachers bring to teacher education. (unpublished doctoral dissertation), Michigan State University, Ann Arbor.

Bransford, J. D., Brown, A. L., \& Cocking, R. R. (Eds.). (1999). How people learn. Washington, DC: National Academy Press.

Bussey, T. J., Orgill, M., \& Crippen, K. J. (2013). Variation theory: A theory of learning and a useful theoretical framework for chemical education research. Chemistry Education Research and Practice, 14(1), 9-22. doi:10.1039/C2RP20145C

Cai, J., Morris, A., Hohensee, C., Hwang, S., Robison, V., \& Hiebert, J. (2017). Making classroom implementation an integral part of research. Journal for Research in Mathematics Education, 48(4), 342-347.

Chapman, O. (2007). Facilitating preservice teachers' development of mathematics knowledge for teaching arithmetic operations. Journal of Mathematics Teacher Education, 10, 341349.

Cobb, P., \& Wheatley, G. (1988). Children's initial understandings of ten. Focus on Learning Problems in Mathematics, 10(3), 1-28. 
Coles, A., \& Brown, L. (2016). Task design for ways of working: Making distinctions in teaching and learning mathematics. Journal of Mathematics Teacher Education, 19(2), 149-168. doi:10.1007/s10857-015-9337-4

Crespo, S., \& Nicol, C. (2006). Challenging preservice teachers' mathematical understanding: The case of division by zero. School Science and Mathematics, 106(2), 84-97.

Fuson, K. C. (1990). A forum for researchers: Issues in place-value and multidigit addition and subtraction learning and teaching. Journal for Research in Mathematics Education, 21, 273-280.

Fuson, K. C., Wearne, D., Hiebert, J. C., Murray, H. G., Human, P. G., Olivier, A. I., .. . Fennema, E. (1997). Children's conceptual structures for multidigit numbers and methods of multidigit addition and subtraction. Journal for Research in Mathematics Education, 28, 130-162.

Graeber, A. O. (1999). Forms of knowing mathematics: What preservice teachers should learn. Educational Studies in Mathematics, 38(3), 189-208. doi:https://doi.org/10.1023/A:1003624216201

Gravemeijer, K. (2004). Local instruction theories as means of support for teachers in reform mathematics education. Mathematical Thinking and Learning: An International Journal, 6(2), 105-128.

Gravemeijer, K., \& Cobb, P. (2006). Design research from the learning design perspective. In J. Van den Akker, K. Gravemerijer, S. McKenney, \& N. Nieveen (Eds.), Educational design research (pp. 17-55). London: Routledge.

Gu, F., Huang, R., \& Gu, L. (2017). Theory and development of teaching through variation in mathematics in china. In R. Haung \& Y. Li (Eds.), Teaching and learning mathematics through variation (pp. 13-41). Rotterdam, The Netherlands: Sense Publishers.

Harel, G. (1998). Two dual assertions: The first on learning and the second on teaching (or vice versa). The American Mathematical Monthly, 105(6), 497-507. doi:10.2307/2589401

Harel, G. (2013). Intellectual need. In K. R. Leatham (Ed.), Vital directions for mathematics education research (pp. 119-151). New York: Springer.

Harkness, S. S., \& Thomas, J. (2008). Reflections on "multiplication as original sin": The implications of using a case to help preservice teachers understand invented algorithms. Journal of Mathematical Behavior, 27(2), 128-137.

Hart, J. (2010). Contextualized motivation theory (cmt): Intellectual passion, mathematical need, social responsibility, and personal agency in learning mathematics. (PhD), Brigham Young University - Provo.

Hiebert, J., \& Wearne, D. (1996). Instruction, understanding, and skill in multidigit addition and subtraction. Cognition and Instruction, 14, 251-283.

Holmqvist, M., Gustavsson, L., \& Wernberg, A. (2008). Variation theory: An organizing principle to guide design research in education. In A. E. Kelly, R. Lesh, \& J. Y. Baek (Eds.), Handbook of Design Research Methods in Education (pp. 111-130). New York: Routledge.

Kaasila, R., Pehkonen, E., \& Hellinen, A. (2010). Finnish pre-service teachers' and upper secondary students' understanding of division and reasoning strategies used. Educational Studies in Mathematics, 73(3), 247-261.

Kamii, C. (1986). Place value: An explanation of its difficulty and educational implications for the primary grades. Journal of Research in Childhood Education, 1(2), 75-86.

Khoury, H. A., \& Zazkis, R. (1994). On fractions and non-standard representations: Pre-service teachers' concepts. Educational Studies in Mathematics, 27(2), 191-204.

Kontorovich, I. (2015). Why do experts pose problems for mathematics competitions? In C. Bernack-Schüler, R. Erens, T. Leuders, \& A. Eichler (Eds.), Views and beliefs in mathematics education: Results of the 19th mavi conference (pp. 171-181). Wiesbaden, Germany: Springer Fachmedien Wiesbaden. 
Kontorovich, I., \& Zazkis, R. (2016). Turn vs. Shape: Teachers cope with incompatible perspectives on angle. Educational Studies in Mathematics, 1-21.

Ma, L. (1999). Knowing and teaching elementary mathematics: Teachers' understanding of fundamental mathematics in china and the united states. Mahwah, NJ: Erlbaum.

Marton, F., \& Booth, S. A. (1997). Learning and awareness. Mahwah, NJ: Lawrence Erlbuam Associates, Inc.

Marton, F., Runesson, U., \& Tsui, A. B. (2004). The space of learning. In F. Marton \& A. B. Tsui (Eds.), Classroom discourse and the space of learning (pp. 3-40). Mahwah, N.J:: Erlbaum.

Marton, F., Tsui, A. B., Chik, P. P., Ko, P. Y., \& Lo, M. L. (2004). Classroom discourse and the space of learning. Mahwah, NJ: Lawrence Erlbaum Associates, Inc.

May, L. J. (1970). Teaching mathematics in the elementary grades. New York: The Free Press.

Menon, R. (2009). Preservice teachers' subject matter knowledge of mathematics. The International Journal for Mathematics Teaching and Learning. Retrieved from www.cimtplymouth.ac.uk/jiournal/menon.pdf website:

National Research Council (Ed.) (2001). Adding it up: Helping children learn mathematics. Washington, DC: National Academy Press.

Overbay, S. R., \& Brod, M. J. (2007). Magic with mayan math. Teaching Mathematics in the Middle School, 12, 340 - 347.

Pang, M. F., Bao, J., \& Ki, W. W. (2017). 'Bianshi' and the variation theory of learning. In R. Huang \& Y. Li (Eds.), Teaching and learning mathematics through variation: Confucian heritage meets western theories (pp. 43-67). Rotterdam, The Netherlands: Sense Publishers.

Ross, S. (2001). Pre-service elementary teachers and place value: Written assessment using a digit-correspondence task. In R. Speiser, C. A. Maher, \& C. N. Walter (Eds.), Proceedings of the twenty-third annual meeting of the north american chapter of the international group for the psychology of mathematics education (Vol. 2, pp. 897-906). Snowbird, UT: ERIC Clearinghouse for Science, Mathematics, and Environmental Education.

Runesson, U. (2006). What is it possible to learn? On variation as a necessary condition for learning. Scandinavian Journal of Educational Research, 50(4), 397-410.

Ryve, A., Larsson, M., \& Nilsson, P. (2013). Analyzing content and participation in classroom discourse: Dimensions of variation, mediating tools, and conceptual accountability. Scandinavian Journal of Educational Research, 57(1), 101-114.

Schwartz, D. L., \& Bransford, J. D. (1998). A time for telling. Cognition and Instruction, 16(4), 475-5223.

Simon, M. (1993). Prospective elementary teachers' knowledge of division. Journal for Research in Mathematics Education, 24(3), 233-254.

Simon, M., \& Blume, G. W. (1992). Mathematization as a component of the concept of ratio-asmeasure: A study of prospective elementary teachers. Paper presented at the Annual Meeting of the American Educational Research Association, San Francisco, CA. http://stats.lib.pdx.edu/proxy.php?url=http://search.ebscohost.com/login.aspx?direct=true $\& \mathrm{db}=$ eric \&AN=ED349175\&site=ehost-live

Steffe, L. P., \& Cobb, P. (1988). Construction of arithmetical meanings and strategies. New York: Springer-Verlag.

Stylianides, A. J., \& Stylianides, G. J. (2009). Proof constructions and evaluations. . Educational Studies in Mathematics, 72(2), 237-253.

Thanheiser, E. (2009). Preservice elementary school teachers' conceptions of multidigit whole numbers. Journal for Research in Mathematics Education, 40(3), 251 - 281. 
Thanheiser, E. (2010). Investigating further preservice teachers' conceptions of multidigit whole numbers: Refining a framework. Educational Studies in Mathematics, 75(3), 241-251. doi:https://doi.org/10.1007/s10649-010-9252-7

Thanheiser, E. (2014). Developing prospective teachers' conceptions with well-designed tasks: Explaining successes and analyzing conceptual difficulties. Journal of Mathematics Teacher Education, 18(2), 141-172. doi:10.1007/s10857-014-9272-9

Thanheiser, E. (2018). Brief report: The effects of preservice elementary teachers' accurate selfassessments in the context whole number. Journal for Research in Mathematics Education.

Thanheiser, E., Philipp, R., Fasteen, J., Strand, K., \& Mills, B. (2013). Preservic e-teacher interviews: A tool for motivating mathematics learning. Mathematics Teacher Educator, 1(2), 137 - 147. doi:https://doi.org/10.5951/mathteaceduc.1.2.0137

The Design-Based Research Collective. (2003). Design-based research: An emerging paradigm for educational inquiry. Educational Researcher, 32(1), 5-8.

Valeras, M., \& Becker, J. (1997). Children's developing understanding of place value: Semiotic aspects. Cognition and Instruction, 15, 265-286.

Woleck, K. R. (2003). Tricky triangles: A tale of one, two, three researchers. Teaching Children Mathematics, 10(1), 40.

Zazkis, R., \& Campbell, S. (1996). Divisibility and multiplicative structure of natural numbers: Preservice teachers' understanding. Journal for Research in Mathematics Education, 27, 540-563.

Zazkis, R., \& Khoury, H. A. (1993). Place value and rational number representations: Problem solving in the unfamiliar domain of non-decimals. Focus on Learning Problems in Mathematics, 15(1), 38-51. 